\title{
Ação empresarial em escala regional: um estudo da permeabilidade do Legislativo do Paraná à ação da Federação das Indústrias do Estado do Paraná (Fiep)
}

na 16a legislatura (2007-2011)*

\author{
Juliano Braga Griebeler** \\ \& Sérgio Braga***
}

Resumo: O objetivo deste texto é fazer um estudo do grau de sucesso e fracasso da Federação das Indústrias do Estado do Paraná (Fiep) diante das propostas apresentadas na Assembleia Legislativa do Paraná na 16ạ legislatura (2007-2011). Para tanto, analisaremos o índice de convergência entre posicionamento da associação industrial paranaense e as proposições que tramitaram no Legislativo estadual, apoiando-nos na metodologia desenvolvida por Mancuso (2007) para a análise da ação parlamentar do empresariado em escala nacional. Procuraremos demonstrar duas proposições básicas: $i$. o grau de sucesso do empresariado paranaense é menor do que aquele observado por outros atores do Legislativo federal; ii. o empresariado paranaense pode ser caracterizado como ator político com baixo grau de capacidade propositiva, mas com elevado poder de veto sobre as propostas que contrariam seus interesses. Dessa forma, buscaremos inserir-nos no debate a respeito da ação política da ação empresarial no período pós-1988, evidenciando algumas de suas singularidades e formas inovadoras de ação coletiva em escala regional.

Palavras-chave: Agenda Legislativa da Indústria; ação empresarial em escala regional; grupos de pressão em escala regional.

\section{Introdução}

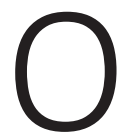
objetivo do presente texto é elaborar um estudo do grau de semelhança entre a agenda de políticas públicas sugeridas pelos industriais paranaenses e as propostas que tramitaram no Legislativo estadual deste estado entre os anos de 2007 a 2011 (16a legislatura na Assembleia Legislativa e governo de Roberto Requião no estado), apoiando-nos na metodologia desenvolvida por Mancuso (2004, 2007a), para verificar o grau de sucesso e fracasso da Federação das Indústrias do Estado do Paraná (Fiep) mediante seu posicionamento expresso na Agenda Legislativa da Indústria do Estado do Paraná (ALIPR). Dessa forma, buscamos inserir-nos no debate a respeito da força/atuação política do empresariado brasileiro no período pós1988, através da mensuração do sucesso e insucesso da indústria no processo legislativo estadual. A ALIPR é uma publicação da Fiep que apresenta os projetos de maior

\author{
* Este artigo \\ apresenta resultados \\ de trabalho \\ realizado no \\ âmbito da pesquisa \\ "Quem são e o que \\ fazem os políticos \\ paranaenses?" Ao \\ avaliar e monitorar \\ a atuação das \\ elites políticas \\ paranaenses pela \\ internet (2007- \\ 2011; 2011-2015), \\ coordenada por \\ Sérgio Braga, \\ que contou com \\ o financiamento \\ parcial do CNPq e \\ da Fiep/Fundação \\ Araucária. \\ Agradecemos \\ aos pareceristas \\ anônimos da revista \\ Sociedade e Estado \\ pelas observações \\ que contribuíram \\ para a melhoria \\ da qualidade da \\ argumentação \\ contida no artigo, \\ embora eventuais \\ erros remanescentes \\ sejam naturalmente \\ de nossa inteira \\ responsabilidade.

\footnotetext{
** Departamento de Ciência Política e Sociologia da Universidade Federal do Paraná (Deciso/ UFPR), graduado em ciências sociais pela UFPR (2010) e mestre em
} 
ciência política pela mesma instituição (2014). Atualmente é analista técnico da Federação das Indústrias do Estado do Paraná (Fiep) no Departamento de Assuntos Legislativos. Tem experiência na área de sociologia política, com ênfase em grupos de interesse, relações governamentais, processo legislativo, lobby e democracia. <julianogriebeler@ gmail.com>

*** Professor do Programa de Pós-Graduação em Ciência Política do Departamento de Ciência Política e Sociologia da Universidade Federal do Paraná (Deciso/ UFPR), doutor em desenvolvimento econômico pelo Instituto de Economia da Unicamp, coordenador do Grupo de Trabalho Ciberativismo, Ciberpolítica e Cibercultura da Associação Nacional de Pós-Graduação em Ciências Sociais (Anpocs) (20142015). relevância para o setor que tramitaram em cada sessão legislativa, com o parecer e o posicionamento do empresariado sobre cada um dos temas em discussão. Através da comparação entre o parecer do empresariado e o resultado final da tramitação, procuraremos demonstrar a hipótese de que o empresariado industrial paranaense é, assim como ocorre com o empresariado industrial em nível nacional e em outras unidades da federação, um ator presente na cena política do estado, conseguindo, em casos pontuais, articular-se coletivamente para fazer seus interesses serem representados e seus objetivos atingidos no processo legislativo. Os resultado obtidos mostram, no entanto, que a grande maioria dos projetos de interesse do empresariado industrial paranaense não são convertidos em novas normas jurídicas, embora praticamente todos os projetos sobre os quais se declaram contrários tenham sido arquivados ao longo da legislatura, caracterizando um ator político com alta capacidade reativa e de veto, mas baixa capacidade propositiva nos órgãos legislativos estaduais.

Nesse contexto, uma importante contribuição da literatura mais recente foi demonstrar que o empresariado brasileiro, especialmente o empresariado industrial, engajou-se num crescente processo de organização e mobilização desde a década de 1990, transcendendo os limites dos arranjos corporativos tradicionais, e que tem nos órgãos legislativos um importante lócus político de atuação (Diniz \& Boschi, 2000; 2004; Mancuso, 2004; 2007a). Assim, especialmente no período pós-1988, o Legislativo ganha maior peso no processo decisório, convertendo-se em importante arena de atuação do empresariado brasileiro e dando origem a um padrão "híbrido" e mais diversificado de representação de interesses, nos quais se articulam a representação corporativa legada de arranjos institucionais anteriores e a representação dos atores empresariais nos órgãos legislativos (Aragão, 1994; Diniz, 2000; Barbosa, 2003). Com a progressiva institucionalização da democracia brasileira no início deste século, é de se esperar que o padrão detectado por estes autores em escala nacional, se difundisse progressivamente também em escala regional, com os diferentes grupos sociais organizando-se para influir nas decisões parlamentares também nos estados e municípios brasileiros.

Nesse contexto de aprofundamento do estudo da atuação dos empresários em órgãos legislativos, pesquisas mais recentes procuraram definir métodos de quantificar o sucesso ou insucesso do empresariado no Legislativo nacional (Mancuso, 2004; 2007a). A quantificação dos sucessos do empresariado no Legislativo contribuiria para o debate a respeito da força política deste grupo, trazendo uma nova luz ao debate a respeito da força ou fraqueza do empresariado, debate este que se trava há muito tempo inclusive na literatura internacional (Boschi, 1979; Costa, 1998; Schneider, 2004, Mancuso, 2007b). Assim, enquanto parcela dos autores defendem o empresariado como ator político estruturalmente fraco e focado nas atividades econômicas, que tenderia a delegar para o governo e para a burocracia de Estado o papel de promotor das políticas de desenvolvimento, encontramos na teoria clássica 
teses que colocam o empresariado como ator privilegiado no processo decisório. Este privilégio seria decorrente da grande quantidade de recursos políticos por eles centralizados e de uma dependência estrutural crônica do Estado em relação ao capital, pois o empresariado teria sob seu controle, nas sociedades capitalistas democráticas, o poder de tomar decisões relativas à atividade econômica que tem grande impacto sobre a sociedade como um todo (Miliband, 1969; Offe, 1984). Entretanto, esta tese a respeito da posição política privilegiada do empresariado nas sociedades capitalistas não é consenso na literatura, com diferentes autores chamando a atenção para o fato de a submissão do Estado e das instituições políticas capitalistas ao interesse do empresariado não ser inexorável em todas as dimensões do processo decisório, mas variar conforme os diferentes contextos sociais nos quais se encontram inseridos estes atores (Vogel, 1987).

O presente trabalho pretender contribuir para este debate a respeito da ação política do empresariado no processo decisório efetuando uma reflexão mais sistemática sobre a relação entre empresários e sistema político estadual. Para abordar estes problemas, seguiremos a seguinte sequencia:

a. inicialmente, faremos um breve histórico da Fiep e de suas atividades políticas recentes, inserindo a agenda legislativa neste contexto;

b. em segundo lugar efetuaremos uma análise da Agenda Legislativa da Indústria, buscando caracterizar a permeabilidade do Legislativo estadual paranaense às demandas do empresariado local;

c. por fim, extrairemos algumas implicações e faremos algumas inferências a respeito dos padrões de comportamento político do empresariado paranaense observado em escala regional.

\section{A Federação das Indústrias do Estado do Paraná e a Agenda Legislativa da Indústria}

Criada em 1944, por um consenso entre os delegados dos diversos sindicatos das indústrias do Paraná acerca da necessidade de sindicalização da classe e das vantagens em unificar a força da indústria em uma federação, a Fiep foi fundada seguindo os mesmos passos de outros estados que já possuíam sua entidade representativa, tais como São Paulo, Rio de Janeiro, Minas Gerais e Rio Grande do Sul. Ao longo de seus 65 anos de existência a Fiep teve sete presidentes, todos importantes nomes no cenário político e econômico estadual", apresentando como objetivo principal "fazer a coordenação, proteção e representação legal das diversas categorias econômicas da indústria, visando a promoção da defesa de seus legítimos interesses" (Fiep, 2011).
1. Os presidentes da Fiep até o momento da redação deste artigo foram: Heitor Stockler de nça (1946-1958); Lydio Paulo Bettega (19581968); Mário de Mari (1968-1974); Altavir Zaniolo (1974 -1986); Jorge Aloysio Weber (1986-1995); Jose Carlos Gomes Carvalho (19952003); Rodrigo Costa da Rocha Loures (2003-2011); Edson Campagnolo (2011 2015). Informações para a redação deste tópico sobre a instituição foram extraídas de <www. fiepr.org.br>. Acesso: Jan. 2013 
Hoje em dia, a associação insere-se em um sistema mais abrangente chamado Sistema Fiep, composto pela própria Fiep, pelo Centro das Indústrias do Estado do Paraná (Ciep), pelo Serviço Nacional de Aprendizagem Industrial (Senai), Serviço Social da Indústria (Sesi), o Instituto Euvaldo Lodi (IEL), e a Universidade da Indústria (Unindus). Ao longo de sua história, a Fiep desempenhou um papel importante na elaboração de políticas para o crescimento industrial paranaense, contribuindo decisivamente para a criação e o desenvolvimento da Cidade Industrial de Curitiba, dentre outras iniciativas. Possui atualmente 100 sindicatos industriais filiados, que representam 40 mil indústrias responsáveis pela geração direta de 700 mil postos de trabalho no estado. A associação tem como bandeira manifesta buscar soluções que permitam o crescimento continuado do setor produtivo, com base nos conceitos de sustentabilidade e responsabilidade social (Fiep, 2011), embora também busque influenciar o processo político estadual, como veremos em seguida.

\section{As atividades políticas da Fiep e a Agenda Legislativa da Indústria}

Assim como as demais associações de representação de interesses empresariais no Brasil, o sistema da Fiep divide-se em diversos subsistemas, sendo que cada um possui uma função e atividade especifica, sendo a federação responsável pelos conselhos temáticos, assessoria sindical e defesa do interesse do empresariado frente aos projetos que tramitam no Legislativo, tanto estadual quanto nacional; o Sesi, responsável pelos temas referentes às iniciativas de responsabilidade social, visa à segurança e à saúde no trabalho, assim como a consultorias nestas áreas; o Senai tem por objetivo tratar de assuntos sobre educação profissional, qualidade e aperfeiçoamento dos profissionais na área, ofertando também cursos técnicos e tecnológico e, por fim, o IEL ocupa-se da área de estágios e novos aprendizes, buscando incorporar os estudantes acadêmicos à realidade profissional. Esse sistema reproduz, em linhas gerais, as organização corporativa também existente em nível nacional e na maior parte dos estados brasileiros (Leopoldi, 2000; Diniz \& Boschi, 2004).

A organização interna da Fiep conta ainda com diversos conselhos setoriais e temáticos (como, por exemplo, os conselhos de assuntos tributários, meio ambiente, micro e pequena empresa, assuntos legislativos, infraestrutura e relações do trabalho). Estes conselhos buscam definir estratégias de solução para os problemas encontrados, cada um em sua respectiva área. Outra característica importante da federação é que ela busca sempre agir de acordo com a demanda das empresas aos sindicatos.

Além desse padrão comum que se encontra também em outras entidades na escala nacional, podemos detectar na Fiep, contudo, especialmente nas gestões de seu presidente Rodrigo Rocha Loures (2008-2012), algumas singularidades relacionadas 
à forte presença da associação nas atividades políticas, com uso intensivo da internet e das tecnologias digitais para promovê-las (Braga \& Nicolás, 2009; Costa \& França, 2012). Dentre essas atividades políticas, algumas buscam efetivamente estimular a participação dos cidadãos e dialogar com o restante da sociedade a respeito de temas de interesse dos empresários. Destacam-se o site Vigilantes da Democracia, a Rede de Participação Política e, por fim, a Agenda Legislativa da Indústria ${ }^{2}$. Estas atividades são exemplificadas abaixo.

\section{Vigilantes da Democracia e \\ o Sistema de Monitoramento dos Eleitos}

O site Vigilantes da Democracia foi uma atividade relacionada a um programa mais abrangente, o Sistema de Monitoramento e Avaliação dos Eleitos, resultado do intercâmbio entre a Fiep e pesquisadores e estudantes do curso de ciências sociais da Universidade Federal do Paraná. A iniciativa teve por objetivo fazer um monitoramento das elites políticas do estado através do acompanhamento das matérias na imprensa e da atuação parlamentar do presidente da República, do governador, dos três senadores, dos 30 deputados federais e 54 deputados estaduais eleitos pelo estado.

Além do monitoramento das notícias, o site também elaborou análises de acontecimentos polêmicos do Legislativo paranaense, bem como o acompanhamento in loco das sessões em plenário e da Comissão de Constituição e Justiça da Assembleia Legislativa do Estado do Paraná (Alep). Todas estas atividades foram divulgadas e atualizadas semanalmente na página apresentada na Figura 1 até o encerramento da atualização do programa em agosto de 2013.

FIGURA 1

SISTEMA DE MONITORAMENTO DOS ELEITOS

<WWW.VIGILANTESDADEMOCRACIA.COM.BR>

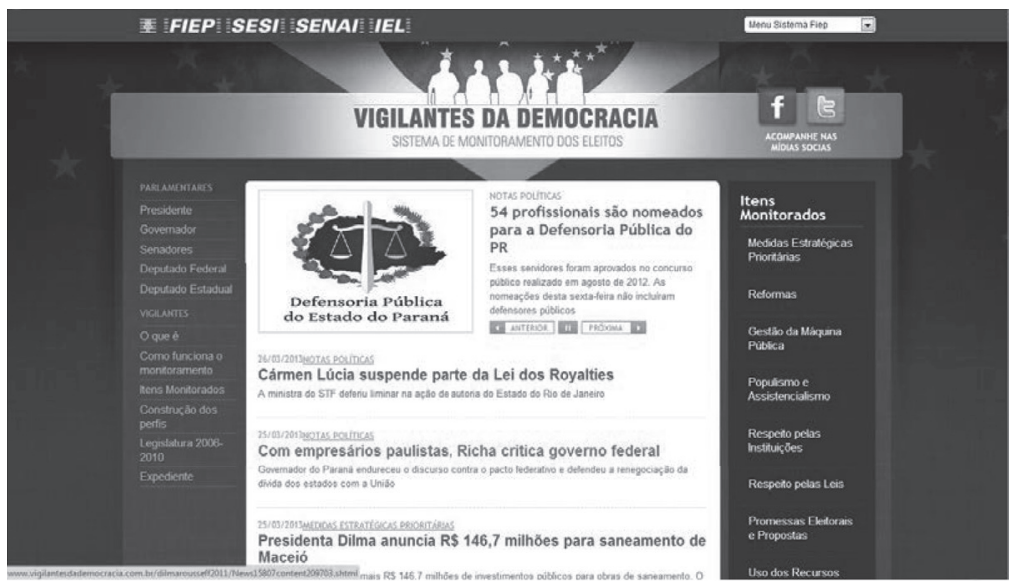

2. Para uma análise em maior profundidade dessas experiências, que usa as tecnologias digitais como importante elemento de difusão, ver o já citado trabalho de Braga \& Nicolás (2009) e o texto mais redente de Costa \& França (2012). 
3. Algumas dessas atividades, tais como o programa Vigilantes da Democracia e a Rede de Participação Política foram encerradas após a posse de Edson Campagnolo na Presidência do órgão, enquanto outras, como a Agenda Legislativa da Indústria e o Sistema de Monitoramento Parlamentar em convênio com pesquisadores da UFPR permaneceram

\section{A Rede de Participação Política}

Além do programa de monitoramento dos eleitos, o portal da Fiep hospedou também, durante a gestão do presidente Rocha Loures, a Rede de Participação Política, uma iniciativa da associação em parceria com a Federação das Associações Comerciais e Empresariais do Paraná (Faciap), que tem como objetivo declarado o de "fomentar a participação, o debate e a ação política através da mobilização dos cidadãos visando o aprofundamento e o aprimoramento da democracia e de suas instituições". Inicialmente chamada de Rede de Participação Política do Empresariado, teve suprimida esta última expressão a partir da avaliação de seus organizadores de que a mesma limitava o campo de ação do programa, restringindo a intenção inicial de tornar a rede um canal no qual a sociedade toda pudesse participar, e não apenas o empresariado ${ }^{3}$.

Como demonstrado por Braga \& Nicólas (2009) e Costa \& França (2012), a característica inovadora da Rede de Participação Política está não apenas no fato de ser uma iniciativa vinculada ao empresariado, o qual é tradicionalmente voltado para as questões econômicas, mesmo nas suas ações políticas, mas principalmente por orientar uma concepção mais ampla e participativa da atividade política, buscando promover a participação e a mobilização de cidadãos em geral em torno de questões relacionadas à representação política, com grande ênfase para os programas de desenvolvimento local em andamento nos bairros da cidade e em atividades comunitárias de cunho social.

O site é o principal instrumento utilizado pela rede, que contou, durante seu período de funcionamento, com mais de seis mil pessoas cadastradas e uma média de 20 mil acessos por mês. Outras iniciativas importantes que giraram em torno da rede destacadas pelos estudos anteriores são:

i. um curso de formação política a distância ministrado inteiramente via internet, e denominado de "Democracia, redes sociais e sustentabilidade", baseado no livro-texto Alfabetização democrática - o que podemos pensar (e ler) para mudar nossa condição de analfabetos democráticos, de autoria do analista político Augusto de Franco;

ii. o site Vigilantes da Democracia, já mencionado;

iii. as plataformas ning e twitter, que tiveram por objetivo constituir um espaço de diálogo entre os participantes; e

iv. O Projeto Político de Desenvolvimento das Cidades, que desenvolveu ações nos bairros de vinte municípios, designando agentes locais para 
conversar com as lideranças comunitárias para o desenvolvimento de ações que não sejam dependentes das ações parlamentares.

Todas as atividades da Rede estiveram vinculadas ao sistema Fiep, conforme pode ser exemplificado pela Figura 2.

FIGURA 2

Rede de PARTICIPAÇÃo PolítICA

(WWW.PARTICIPACAOPOLITICA.ORG.BR)

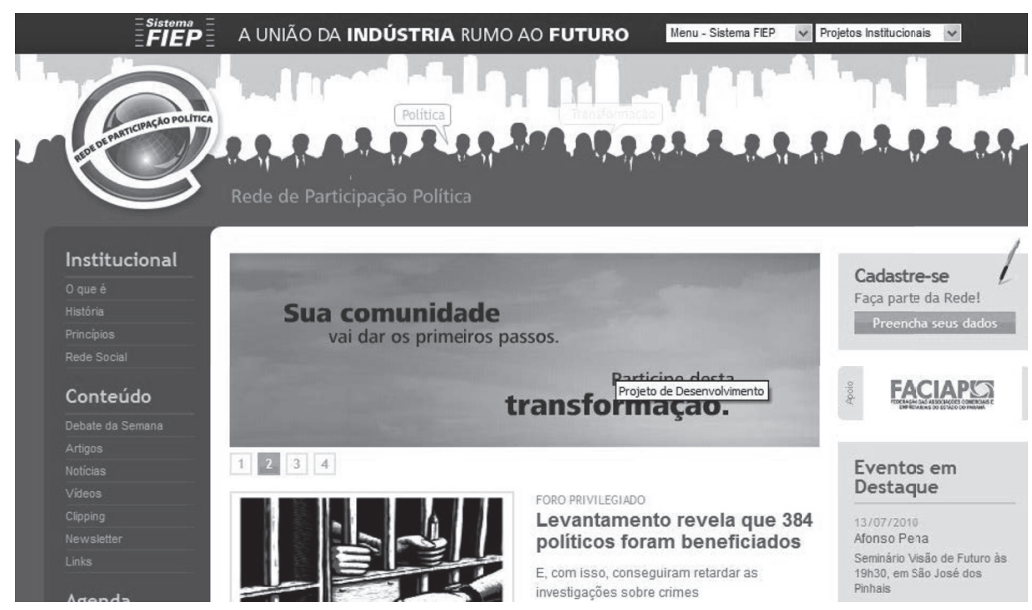

\section{A Agenda Legislativa da Indústria}

Por fim, uma terceira atividade política de destaque promovida pela Fiep é a Agenda Legislativa da Indústria do Paraná, que, em geral, segue os mesmos moldes da iniciativa desenvolvida pelo CNI e por outras associações empresariais, esta em escala estadual. A agenda legislativa é publicada desde 2005 e tem por objetivo acompanhar e pronunciar-se publicamente sobre os projetos em relação aos quais a indústria apresenta algum interesse ou posicionamento convergente e divergente, não se atendo apenas a assuntos econômicos, mas também a outros temas com impacto sobre a sociedade (econômico-financeiros, sociais, políticos etc.).

O processo de elaboração da agenda legislativa tem início na Alep, onde a assessoria legislativa faz o acompanhamento de todas as sessões e filtra os projetos apresentados, dando ênfase aos que são de interesse da indústria. Após esta seleção, é feito um acompanhamento da tramitação da matéria, informando os possíveis setores afetados pelo projeto, através de um consulta on-line realizada através de formulário específico. Sublinhe-se que, conforme pudemos verificar através de entrevistas com 
os responsáveis pela elaboração dos documentos, a assessoria legislativa preocupa-se sempre em agir segundo as diretrizes do chamado lobby branco, ou seja, aquele que não recorre a meios de corrupção e suborno para atingir seus interesses e procurando dar o máximo de publicidade às suas ações, através de um processo de consulta efetiva aos associados.

Como segundo passo para formulação da agenda legislativa, o Departamento de Assuntos Legislativos (DAL) encaminha a todos os sindicatos e coordenadores dos conselhos temáticos, assim como a seus técnicos, o Caderno de priorização, que reúne todos os projetos que tramitaram ao longo do ano para que os sindicatos se posicionem de acordo com a prioridade da proposta. Em fevereiro, é feita a compilação de todas as respostas enviadas e é realizado o Encontro de Convergência da Agenda Legislativa. Neste encontro, os sindicatos decidem quais dos projetos presentes no caderno irão compor efetivamente a agenda legislativa, definindo a prioridade e o posicionamento, assim como o parecer ao projeto.

Durante a consulta aos associados, as proposições são classificadas segundo critérios tais como posicionamento da indústria (convergente, convergente com ressalvas, divergente e divergente com ressalvas) e em resultados possíveis da tramitação da proposição (transformada em nova norma jurídica, prejudicada, rejeitada, retirada pelo autor e arquivada). Após a análise dos resultados, um documento com o título de Agenda Legislativa da Indústria é divulgado amplamente pela coletividade paranaense e disponibilizado no site da associação, conforme mostra a Figura 3.

FIGURA 3

A ASSESSORIA LEGISLATIVA DA FIEP

E A AGENDA LEGISLATIVA DA INDÚSTRIA

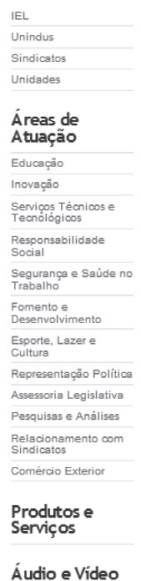

Assessoria Legislativa

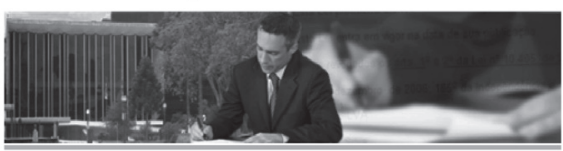

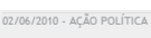

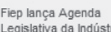

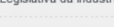

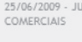

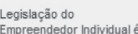

Empreendededor hadvidual
tema de encontro em Fo

toma de

Departamento criado para monitorar a apresentação e tramitação de projetos de lei no âmbito federal e estadual que tenham algum impacto sobre o setor industrial. Trabalha na defesa de interesses dos empresários paranaenses, Identifica as proposiç̧ęes de interesse da indústria, divulgando-as e formulando alternativas convergentes com a agenda do setor. Este trabalho é divulgado na Agenda Legislativa da Indústria do Estado do Paraná, publicação anual que reúne os principais temas de interesse que tramitam no parlamento durante 0 ano Legislativo. Mais informações no site (www flep.legisdata.cni.org.br)

FIEP

Agenda Legislativa

Panorama Industrial

25/106/2009 - LEGISLATIO

Fipp busca maior
appoximacäo con appoximaçăio con
Legisativo

10106/2010- PROPOSTI Zel da Transparênclés28,05/2010-TRAOSPAR cidades está pronta para FIEP - Federação das Indústrias do Assessoria de Assuntos Legislativos Estado do Paranà

Agenda Legislativa abiri gastos, die CNMA 
Como observado por estudiosos da ação política empresarial brasileira (Diniz \& Boschi, 2000; 2004; 2009), a partir da década de 1990 os efeitos econômicos e políticos provocados pelas políticas liberais implantadas durantes as gestões de Collor e Fernando Henrique Cardoso foram fundamentais para a unificação do empresariado brasileiro em torno de objetivos comuns. Nesse período, o acirramento da concorrência e a abertura comercial tornaram-se um dos pontos fundamentais de mobilização do empresariado, contribuindo para mobilizá-lo em torno da redução do "custo Brasil", movimento que teve na arena legislativa um espaço político fundamental de atuação (Mancuso, 2004; 2007a). A principal entidade responsável pela união do empresariado brasileiro e por sua mobilização junto aos órgãos parlamentares foi a Confederação Nacional da Indústria (CNI), que tomou a iniciativa de organizar a ação coletiva do setor. Um dos desdobramentos deste movimento contra o "custo Brasil" foi a divulgação, pela entidade, a partir de 1996, da Agenda Legislativa da Indústria, publicação que mostra a posição do setor diante das proposições legislativas que tramitam no Congresso Nacional. Posteriormente, a iniciativa ficaria consolidada e se ampliaria, sendo também reproduzida por diversas federações industriais em escala regional (Braga \& Nicólas, 2009)4.

No caso específico da Fiep, a partir de sua divulgação inicial em 2005, houve um crescente esforço da associação na utilização dos recursos da internet para sua elaboração, com criação de uma plataforma digital, o Legisdata ${ }^{5}$, para mobilização e consulta aos associados, e com a divulgação periódica das agendas legislativas através do website da instituição e em formato pdf. O Legisdata é um sistema on-line de base de dados, atualizados com o acompanhamento dos projetos de interesse do setor que tramitam no Legislativo. Inicialmente utilizado pela CNI, a plataforma foi transposta para outras federações, sendo utilizada também por outras federações que efetuam acompanhamento sistemático da tramitação das proposições legislativas em seus estados. Nela encontram-se os projetos, com seus autores, ementas, tramitação, relatores etc., assim como o parecer da indústria diante do projeto. É importante ressaltar que para acessar o conteúdo presente no Legisdata é necessário login e senha, não sendo aberto ao grande público.

Já a Agenda Legislativa da Indústria, conforme afirmamos anteriormente, é uma publicação anual que, segundo o posicionamento da própria Fiep,

consolida o propósito de expor, de forma clara e transparente, o posicionamento da Fiep e dos sindicatos empresariais a ela filiados a respeito de projetos legislativos que, em alguma medida, interferem na produção e na competitividade da indústria paranaense (ALIPR, 2005: 25).

Até o momento da redação deste texto, haviam sido divulgadas sete agendas legislativas, todas elas disponíveis no website da instituição ${ }^{6}$. Além disso, são divulgadas

\author{
4. No momento de \\ redação deste artigo, \\ nove federações \\ das indústrias de 27 \\ estados brasileiros \\ divulgavam \\ trabalhos de sua \\ agenda legislativa \\ on-line. \\ 5. <www.fiep. \\ legisdata.cni.org. \\ $\mathrm{br} />$. \\ 6. <http://www. \\ fiepr.org.br/para-sin- \\ dicatos/FreeCom- \\ ponent20715con- \\ tent170372.shtml>. \\ Acesso em: Mar. \\ 2013.
}


também newsletters semanais para as pessoas cadastradas, associadas ou não, com informações sobre medidas de interesse da indústria publicadas no Diário Oficial, notícias relacionadas à indústria e também sobre proposições em tramitação no Legislativo nacional e estadual.

São estes documentos, além dos materiais internos utilizados como instrumentos de consulta aos associados para a elaboração das análise pela assessoria, que se constituem em matéria-prima da análise apresentada a seguir.

\section{Metodologia de análise:}

mensurar sucesso e insucesso do

\section{empresariado através da agenda legislativa}

Para realizar a análise do grau de sucesso ou insucesso para o empresariado industrial paranaense no Legislativo, baseamo-nos na metodologia desenvolvida por Wagner Pralon Mancuso que, em sua obra O lobby da indústria no Congresso Nacional (Mancuso, 2007), defende a tese de que é possível classificar as proposições de maior relevância para a indústria em sucesso ou insucesso de acordo com a correspondência existente entre o parecer formulado nas agendas e o resultado final da proposição. Mancuso classifica em cinco as modalidades possíveis de resultados da tramitação de uma proposição legislativa, sendo que, neste trabalho, acrescentamos o veto como modalidade adicional, visto que este critério pode servir como indicador de fenômenos politicamente significativos, tais como a maior ou menor permeabilidade do Executivo às demandas deste segmento empresarial. Além disto, nossa metodologia difere da de Mancuso por suprimirmos o item sobre matérias prejudicadas, devido à pouca informação sobre o resultado destas proposições, de forma que não há como saber se foram rejeitadas por serem inconstitucionais ou por já existirem outros projetos tramitando no Legislativo de conteúdo semelhante. Sendo assim, são cinco os resultados possíveis da tramitação de uma proposição:

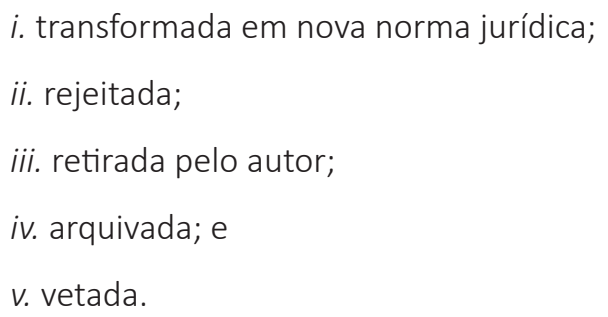

Buscamos relacionar cada um destes resultados com o parecer da indústria aos projetos que tramitaram no Legislativo. O Quadro 1 apresenta as diferentes combinações possíveis. 
Como observa Mancuso (2007), podemos agregar ainda a esta tipologia, as categorias "sucessos e insucessos parciais", construídas a partir dos "pareceres com ressalvas" da indústria, o que nos permitiria efetuar uma abordagem mais matizada do grau de semelhança entre parecer da indústria e resultado das proposições legislativas, evitando uma concepção dicotômica de "tudo ou nada".

Feitas estas ressalvas, as categorias empregadas em nossa metodologia podem ser resumida como mostra o "Quadro 2".

Além dos aspectos mencionados, há uma diferença em relação à abordagem desenvolvida por Mancuso no tocante ao destaque dado ao tema do "custo Brasil". Mancuso faz sua análise dos temas que vigoram na Agenda Legislativa da Indústria da CNI e que tratam do "custo Brasil", fazendo dessa forma uma análise dos projetos que interferem no status quo, classificando-os em sucessos e insucessos ${ }^{7}$. As-

sim, a aprovação de projetos que reduzem o "custo Brasil" ou impedem seu aumento seriam um sucesso para o setor, enquanto a rejeição destes seriam um insucesso; da mesma forma, a aprovação de projetos que aumentam o "custo Brasil" ou que impedem a redução do mesmo seriam um insucesso para o setor. Neste trabalho, não focaremos neste tema específico pelo fato de a Agenda Legislativa da Indústria estadual não se pautar pelo mesmo foco temático, ou seja, ela não tem como objetivo
RESULTADO DA TRAMITAÇÃO $\times$ PARECER DA INDÚSTRIA

\begin{tabular}{|c|c|c|}
\hline Decisão & Parecer & (in)Sucesso \\
\hline nova norma jurídica & Convergente & Sucesso \\
\hline nova norma jurídica & Convergente com ressalvas & Sucesso \\
\hline nova norma jurídica & Divergente & Insucesso \\
\hline nova norma jurídica & Divergente com ressalvas & Insucesso \\
\hline Rejeitada & Convergente & Insucesso \\
\hline Rejeitada & Convergente com ressalvas & Insucesso \\
\hline Rejeitada & Divergente & Sucesso \\
\hline Rejeitada & Divergente com ressalvas & Sucesso \\
\hline Retirada pelo autor & Convergente & Insucesso \\
\hline Retirada pelo autor & Convergente com ressalvas & Insucesso \\
\hline Retirada pelo autor & Divergente & Sucesso \\
\hline Retirada pelo autor & Divergente com ressalvas & Sucesso \\
\hline Arquivada & Convergente & Insucesso \\
\hline Arquivada & Convergente com ressalvas & Insucesso \\
\hline Arquivada & Divergente & Sucesso \\
\hline Arquivada & Divergente com ressalvas & Sucesso \\
\hline Vetada & Convergente & Insucesso \\
\hline Vetada & Convergente com ressalvas & Insucesso \\
\hline Vetada & Divergente & Sucesso \\
\hline Vetada & Divergente com ressalvas & Sucesso \\
\hline
\end{tabular}

Fonte: Elaboração própria.

\section{QUADRO 2}

SUCESSOS E INSUCESSOS DA INDÚSTRIA

\begin{tabular}{|c|c|c|}
\hline Parecer Fiep & Resultado da tramitação & Sucesso/Insucesso \\
\hline Convergente & Convertido em lei & Sucesso (parcial) \\
\hline Convergente & Arquivado/Vetado & Insucesso (parcial) \\
\hline Divergente & Convertido em lei & Insucesso (parcial) \\
\hline Divergente & Arquivado/Vetado & Sucesso (parcial) \\
\hline
\end{tabular}

7. “Custo Brasi"” foi uma expressão utilizada especialmente a partir dos anos 1990 por setores empresariais para resumir o conjunto de fatores que prejudicam a competitividade das empresas nacionais frente às de outros países. 
específico a atuação da indústria em itens que afetem o "custo Brasil", apontado por Mancuso como o principal quesito enfatizado na agenda da indústria na década de 1990. No caso das agendas legislativas estaduais da atual conjuntura (incluindo a da Fiep), elas destacam o objetivo mais amplo de serem um canal de comunicação entre os empresários, o Legislativo e a sociedade civil, buscando tornar transparentes os interesses da indústria diante dos projetos que tramitam no Legislativo estadual, pelo que incorporam um universo temático mais amplo do que as agendas da conjuntura examinada por Mancuso.

É interessante observar que os sucessos e insucessos adquirem características diferentes de acordo com o posicionamento da indústria e o resultado final. Mancuso afirma que a ação de pressão do empresariado pode visar a dois fins: alterar o status quo para melhor, o que seria uma atitude ofensiva; ou impedir que o status quo piore, representando uma atitude defensiva. Dessa forma, autor classifica os sucessos em quatro categorias, tal como apresenta o Quadro 3.

QUADRO 3

IMPACTO SOBRE O STATUS QUO

\begin{tabular}{|l|c|c|}
\hline \multirow{2}{*}{ Impacto sobre o status quo } & \multicolumn{2}{|c|}{ Resultado da decisão } \\
\cline { 2 - 3 } & Sucesso & Insucesso \\
\hline Status quo muda & Ganho & Perda \\
\hline Status quo mantém-se & Alívio & Frustração \\
\hline Fonte: Mancuso (2007). & & \\
\hline
\end{tabular}

Assim, Mancuso define duas categorias de sucessos e duas de insucessos políticos, de acordo com o posicionamento da indústria e o resultado da tramitação: um projeto que altera o status quo para melhor, quando aprovado, representa um ganho para a indústria; um projeto que piora o status quo, e é por

tanto de interesse contrário à indústria, quando rejeitado, significa um alívio para o empresariado. Já um projeto que altera o status quo para pior, quando aprovado, representa uma perda para a indústria, e um projeto que altera o status quo para melhor, quando rejeitado, resulta em frustração para a indústria.

Antes de prosseguir, é importante ressaltar as possibilidades e limitações deste tipo de enfoque. Com efeito, embora seja possível taxar como sucesso e insucesso para a indústria a tramitação final de uma proposição, não é possível afirmar que tal resultado deu-se, de fato, devido à ação da indústria. Como demonstrado por Mancuso, para afirmar que o resultado $x$ foi devido a influência de $A$, é necessário poder afirmar que caso não houvesse a influência de $A$ o resultado não seria o mesmo. Em nosso enfoque, embora não possamos afirmar que os resultados finais dos projetos se deram por pressão da indústria, é indiscutível que um resultado ao qual o setor demonstrou um parecer positivo, e que, independente do motivo, foi convertido em lei, pode ser classificado como sucesso para o empresariado. Assim sendo, na análise aqui empreendida não nos preocupamos em analisar detalhadamente como é efetivamente organizado o lobby da indústria no Legislativo, como é organizada a 
representação direta do empresariado através de deputados mais vinculados aos interesses do setor, e/ou como a Fiep desenvolveu sua ação para fazer com que os projetos fossem ou não aprovados. Limitamo-nos a analisar os graus de sucessos e insucessos através da análise do resultado da tramitação dos projetos de interesse do empresariado industrial no Legislativo paranaense. Dessa forma, referimo-nos ao sucesso como um sucesso para a indústria e não um sucesso da indústria, pois neste caso estaria subentendido um sucesso da ação da indústria em decorrência de sua atuação direta como lobby ou grupo de pressão, e referimo-nos aos resultados como sucessos para a indústria, independente de decorrer diretamente de uma efetiva pressão da Fiep. Entretanto, vale repetir que, mesmo feita esta ressalva, a análise da correspondência entre tomada pública de posição e resultado de um tema da agenda pública pode ser considerado como indicador indireto relativamente robusto da influência de um determinado grupo social junto ao parlamento, bem como de sua atividade política em escala regional.

O presente trabalho tem por intuito contribuir empiricamente com o debate sobre a ação do empresariado, efetuando uma análise dos sucessos e insucessos da indústria e não aceitando a postulação ex ante da existência de uma inevitabilidade de resultados diante de um posicionamento privilegiado da burguesia industrial no processo decisório, ao menos no nível de abstração em que o estamos analisando neste artigo ${ }^{8}$.

\section{Sucessos e insucessos da indústria paranaense no Legislativo estadual (2005-2010)}

Para a análise dos sucessos e insucessos para a indústria no processo decisório do Legislativo utilizamos todos os projetos de lei presentes nas Agendas Legis/ativas da Indústria do Paraná, publicadas desde 2005 e que tiveram sua tramitação concluída até o final da 16. legislatura. É importante ressaltar que utilizamos as agendas que foram publicadas tanto durante a 15. a legislatura da Assembleia Legislativa, quanto da 16. - legislatura. O motivo que nos levou a considerar ambas as legislaturas deveu-se à baixa mudança no quadro político da assembleia (concorreram 47 deputados à reeleição, entraram 19 novos parlamentares, o que representa uma renovação de 35\%, sendo que destes 19, apenas seis estrearam como deputados no Legislativo estadual), assim como das reeleições nos cargos executivos do governador do estado, no caso Roberto Requião (PMDB), e do presidente da República, Luiz Inácio Lula da Silva (PT), o que assegurou uma certa conti-
TABELA 1

PROJETOS PRESENTES NAS

AGENDAS LEGISLATIVAS (2005-2010)

TABELA 1
PROJETOS PRESENTES NAS
AGENDAS LEGISLATIVAS
\begin{tabular}{|l|c|c|}
\hline \multicolumn{2}{|c|}{ (2005-2010) } \\
\hline Projetos presentes nas agendas & \multicolumn{2}{|c|}{ Total } \\
\hline Projetos em tramitação & 42 & $20,50 \%$ \\
\hline Tramitação concluída & 163 & $79,50 \%$ \\
\hline & 205 & $100,00 \%$ \\
\hline
\end{tabular} Fonte: Elaboração própria com dados das Agendas Legislativas da Indústria do
Paraná.
Paraná.

\footnotetext{
8. Para ser mais claro: não se trata de abordar o problema mais geral da ação política de classe ou de um setor específico do empresariado, mas de examinar com vagar um problema mais específico: o da ação legislativa do empresariado em escala regional e suas eventuais especificidades em relação ao que é observado em escala nacional por outros analistas.
} 
TABELA 2

RESULTADO DA TRAMITAÇÃO DOS PROJETOS DE LEI

\begin{tabular}{|l|r|r|}
\hline \multicolumn{1}{|c|}{ Resultado da tramitação } & \multicolumn{2}{c|}{ Total } \\
\hline Convertidos em lei & 18 & $11,04 \%$ \\
\hline Proposições rejeitadas & 71 & $43,56 \%$ \\
\hline Proposições retiradas pelo autor & 18 & $11,04 \%$ \\
\hline Proposições arquivadas ao final da legislatura & 32 & $19,64 \%$ \\
\hline Vetados & 24 & $14,72 \%$ \\
\hline Total & 163 & $100,00 \%$ \\
\hline
\end{tabular}

nuidade no quadro político estadual no período em tela. O total de projetos analisado está resumido na Tabela 1.

Dos 205 projetos de interesse da indústria que se encontravam presentes nas agendas legislativas, 42 $(20,5 \%)$ ainda continuavam em tramitação no final da

16. Iegislatura, enquanto 163 (79,5\%) tiveram sua tramitação concluída. O resultado da tramitação do projeto é apresentado na Tabela 2.

Dos 163 projetos de lei que tiveram sua tramitação concluída, 18 (11,04\%) foram convertidos em lei; 71 (43,56\%) foram rejeitados, tanto em comissões, quanto em plenário ou por terem sido prejudicados; 18 (11,04\%) foram retirados a pedido do autor; 32 (19,64\%) proposições arquivadas devido ao término da legislatura; e 24 (14,72\%) projetos foram vetados. Os projetos vetados merecem atenção especial. Destes 24 projetos vetados, apenas três chegaram realmente ao final de sua tramitação, todos os demais aguardavam a pauta de votação ao final da legislatura. Contudo, vários projetos estão aguardando votação há alguns anos, o que demonstra que o objetivo do veto foi atingido, apesar de não ter sido votado, ou seja, o veto conseguiu impedir a promulgação de tais leis. A relação entre o resultado da tramitação dos projetos e o parecer da indústria é apresentado na Tabela 3.

Pode-se perceber que as Agendas Legislativas da Indústria do Paraná são constituídas, em sua maioria, por projetos em que a Fiep apresenta um parecer favorável. Dos 163 projetos presentes com tramitação concluída, a federação declarou parecer convergente a 145 (88,95\%), e divergente de apenas 18 (11,05\%). Dos projetos presentes $71(43,56 \%)$, foram rejeitados e apenas $18(11,04 \%)$ convertidos em nova norma

TABELA 3

PARECER DA INDÚSTRIA $\times$ RESULTADO DA TRAMITAÇÃO

\begin{tabular}{|c|c|c|c|c|c|c|c|c|c|c|c|c|}
\hline 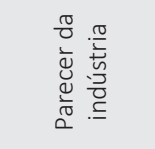 & & 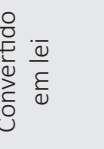 & & 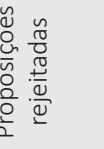 & & 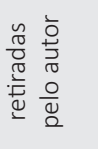 & 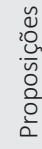 & 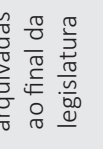 & & $\begin{array}{l}\tilde{0} \\
\frac{0}{0} \\
\frac{\pi}{0} \\
0\end{array}$ & & $\begin{array}{l}\underset{\mathbb{\sigma}}{0} \\
\stackrel{0}{0}\end{array}$ \\
\hline Convergente & 17 & $10,43 \%$ & 61 & $37,43 \%$ & 17 & $10,43 \%$ & 29 & $17,80 \%$ & 21 & $12,88 \%$ & 145 & $88,95 \%$ \\
\hline Divergente & 1 & $0,61 \%$ & 10 & $6,13 \%$ & 1 & $0,61 \%$ & 3 & $1,84 \%$ & 3 & 1,84 & 18 & $11,05 \%$ \\
\hline Total & 18 & $11,04 \%$ & 71 & $43,56 \%$ & 18 & $11,04 \%$ & 32 & 19,64 & 24 & $14,72 \%$ & 163 & $100,00 \%$ \\
\hline
\end{tabular}

Fonte: Elaboração própria com dados das Agendas Legislativas da Indústria do Paraná. 
TABELA 4

SUCESSOS E INSUCESSOS DA INDÚSTRIA

\begin{tabular}{|c|c|c|c|c|c|c|c|c|c|c|c|c|}
\hline \multirow[b]{2}{*}{ Sucesso } & \multicolumn{2}{|c|}{$\sum_{\substack{0 \\
0}}^{\frac{0}{ \pm}} \frac{\bar{v}}{\varepsilon}$} & \multicolumn{2}{|c|}{ 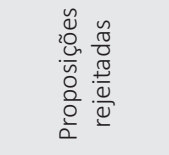 } & \multicolumn{2}{|c|}{ 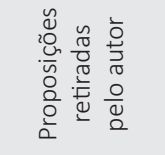 } & \multicolumn{2}{|c|}{ 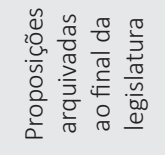 } & \multicolumn{2}{|r|}{$\begin{array}{l}\tilde{0} \\
\frac{0}{0} \\
\tilde{J} \\
\stackrel{0}{\infty}\end{array}$} & \multicolumn{2}{|r|}{$\begin{array}{l}\overline{\mathbb{\pi}} \\
\stackrel{0}{0}\end{array}$} \\
\hline & 17 & $10,43 \%$ & 10 & $6,13 \%$ & 1 & $0,61 \%$ & 3 & $1,84 \%$ & 3 & $1,84 \%$ & 34 & $20,85 \%$ \\
\hline Insucesso & 1 & $0,61 \%$ & 61 & $37,43 \%$ & 17 & $10,43 \%$ & 29 & $17,80 \%$ & 21 & $12,88 \%$ & 129 & $79,15 \%$ \\
\hline Total & 18 & $11,04 \%$ & 71 & $43,56 \%$ & 18 & $11,04 \%$ & 32 & $19,64 \%$ & 24 & $14,72 \%$ & 163 & $100,00 \%$ \\
\hline
\end{tabular}

jurídica. Houve mais proposições vetadas 24 (14,72\%) do que convertidas em lei. De 145 projetos com o parecer convergente, apenas 17 foram convertidos em lei; dos 18 divergentes, apenas 1 foi convertido em lei.

Ao constatar o número de projetos presentes nas agendas que tiveram sua tramitação concluída, o resultado de sua tramitação e o parecer da indústria, partiremos agora para a análise do grau de sucesso e insucesso do empresariado no processo decisório do Legislativo.

Ao relacionar o resultado final da tramitação com o parecer da indústria, obtivemos os seguintes resultados: dos 18 projetos convertidos em lei, 17 representaram sucesso para a indústria, e apenas 1 insucesso. No tocante às proposições rejeitadas, a Fiep foi divergente em relação a 17 projetos, obtendo, portanto, 17 sucessos, e convergente com 128, o que nos dá um grau de insucessos de total de 129 (79,15\%). Do total de manifestações da Fiep, apenas 34 (20,85\%) podem ser consideradas bem-sucedidas, evidenciado que a inclusão de uma proposição na agenda legislativa não é condição suficiente para sua aprovação. Se comparamos estes dados com os obtidos por Mancuso em sua análise do Congresso Nacional, verificamos que a taxa de sucesso da indústria no estado do Paraná é bem inferior: apenas 20,8\% das manifestações podem ser consideradas bem-sucedidas, contra $66,7 \%$ em nível nacional, o que indica uma maior probabilidade do empresariado nacional em ser bem-sucedido em suas demandas legislativas.

Algumas explicações poderiam ser formuladas para explicar essa diferença encontrada entre o sucesso da agenda legislativa industrial nas esferas estadual e federal. Em primeiro lugar, a competência de legislar sobre temas que impactam diversos setores e regulam a economia do país faz com que o Congresso Nacional seja um espaço fundamental de ação empresarial, enquanto os legislativos estaduais, apesar de contar com poderes para fazer modificações significativas, não discutem projetos tão fundamentais - tais como alterações na legislação trabalhista, sistema tributário e normas gerais. Isto poderia significar que o empresariado empenha seus esforços mais nas 
discussões na esfera federal e, portanto, teria mais sucesso nesse contexto. Entretanto, esta hipótese assume que o empresariado é um ator que tem a força para influir nas deliberações políticas. Uma outra explicação poderia ser de natureza institucional, na medida em que a vigência de um presidencialismo excessivamente centralizado nas esferas regionais de governo reduziria a possibilidade de aprovação num sentido favorável aos interesses industriais de proposições que tramitassem pelo Legislativo, em virtude de suas prerrogativas reduzidas em relação ao Executivos estadual.

Para caracterizar melhor os ganhos e as perdas da indústria por setor, efetuamos uma análise desagregada das taxas de sucesso e fracasso por assunto, utilizando para tanto a classificação em sete temas gerais, e respectivos subtemas utilizadas pela ALIPR. Estes assuntos são os mesmos utilizados pela assessoria legislativa da Fiep para classificar as proposições:

i. assuntos econômicos (política industrial, política agroindustrial, fomento e desenvolvimento tecnológico, direito do consumidor, política pública);

ii. infraestrutura (transportes, energia);

iii. meio ambiente (desenvolvimento sustentável, gestão de recursos hídricos, gestão de recursos sólidos);

iv. responsabilidade social;

v. tributos (impostos, taxas e tarifas);

vi. política social (inclusão social, educação, segurança pública, saúde); e vii. questões institucionais.

Os dados desagregados estão resumidos na Tabela 5.

TABELA 5

SUCESSOS E INSUCESSOS POR ASSUNTO

\begin{tabular}{|c|c|c|c|c|c|c|c|c|c|c|c|c|c|c|c|c|}
\hline \multirow[b]{2}{*}{ Sucesso } & \multicolumn{2}{|c|}{ 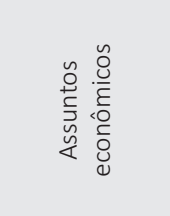 } & \multicolumn{2}{|r|}{ 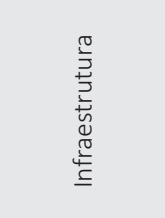 } & \multicolumn{2}{|c|}{ 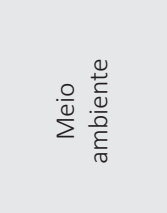 } & \multicolumn{2}{|c|}{ 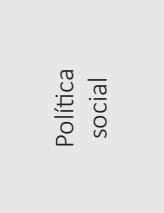 } & \multicolumn{2}{|c|}{ 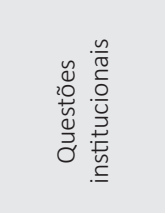 } & \multicolumn{2}{|c|}{ 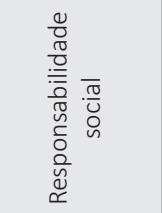 } & \multicolumn{2}{|r|}{$\begin{array}{l}\tilde{0} \\
\frac{0}{5} \\
\frac{0}{2} \\
\text { 른 }\end{array}$} & \multicolumn{2}{|r|}{$\begin{array}{l}\bar{\pi} \\
\stackrel{\widetilde{0}}{\circ}\end{array}$} \\
\hline & 10 & $6,13 \%$ & 6 & $3,68 \%$ & 8 & $4,90 \%$ & 6 & $3,68 \%$ & 2 & $1,22 \%$ & 0 & $0,00 \%$ & 2 & $1,22 \%$ & 34 & $20,85 \%$ \\
\hline Insucesso & 29 & $17,80 \%$ & 12 & $7,36 \%$ & 13 & $7,98 \%$ & 33 & $20,24 \%$ & 12 & $7,36 \%$ & 4 & $2,45 \%$ & 26 & $15,95 \%$ & 129 & $79,15 \%$ \\
\hline Total & 39 & $23,93 \%$ & 18 & $11,04 \%$ & 21 & $12,88 \%$ & 39 & $23,92 \%$ & 14 & $8,58 \%$ & 4 & $2,45 \%$ & 28 & $17,17 \%$ & 163 & $100,00 \%$ \\
\hline
\end{tabular}


Pelos dados, podemos verificar que projetos econômicos relacionados à política social compõem praticamente a metade dos projetos presentes nas agendas, com 39 projetos apreciados em cada uma destas rubricas, indicando serem estas as questões temáticas prioritárias do ponto de vista do empresariado industrial paranaense. Entretanto, os projetos sobre assuntos econômicos apresentaram uma taxa bem superior de sucesso $(25,6 \%)$, quando comparados com as proposições sobre política social com apenas $15,4 \%$ de projetos bem-sucedidos. Proporcionalmente, a área temática na qual o empresariado industrial obteve maior índice de sucesso foi a do meio ambiente, concretizando suas demandas em 8 dos 13 projetos apresentados (61,6\%). Por outro lado, no tocante às proposições legislativas que abordavam o tema tributos, uma das áreas mais sensíveis aos interesses empresariais, visto ser conhecida a reivindicação setorial por uma redução e maior racionalização da carga tributária, constatou-se um dos índices mais baixos de atendimento de demandas ( 2 em 28 projeto, o que corresponde a $16,7 \%)$, indicando uma baixa capacidade propositiva do setor no tocante a este item.

Para refinar mais a análise, removemos os projetos que dizem respeito à política social e a questões propriamente institucionais. Vale ressaltar que esta opção se deu pelo fato de vários projetos que constam na agenda nestes temas, não impactam diretamente o setor produtivo, sendo uma forma de demonstrar o posicionamento da entidade diante de questões que dizem respeito a problemas sociais ou de funcionamento burocrático da máquina pública. Isto foi apontado pela equipe elaboradora da publicação durante a realização das entrevistas e verificado através de uma análise qualitativa dos projetos.

Ao analisar apenas os projetos que podem influenciar as atividades econômicas do setor, encontramos um leve acréscimo na taxa de sucesso, passando de 20,85\% para

TABELA 6

SUCESSO DA INDÚSTRIA POR ASSUNTO

\begin{tabular}{|c|c|c|c|c|c|c|c|c|c|c|c|c|}
\hline & & 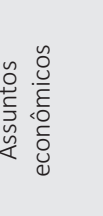 & & 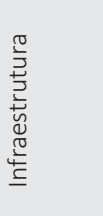 & & 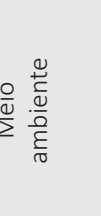 & & . & & 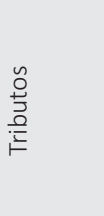 & & $\begin{array}{l}\overline{\widetilde{\pi}} \\
\stackrel{0}{0}\end{array}$ \\
\hline Convergente & 33 & $30,00 \%$ & 13 & $11,81 \%$ & 17 & $15,72 \%$ & 4 & $3,63 \%$ & 28 & $25,45 \%$ & 95 & $86,36 \%$ \\
\hline Divergente & 6 & $7,72 \%$ & 5 & $5,54 \%$ & 4 & $3,63 \%$ & 0 & $0,00 \%$ & 0 & $0,00 \%$ & 15 & $16,64 \%$ \\
\hline Total & 39 & $37,72 \%$ & 18 & $16,35 \%$ & 21 & $19,08 \%$ & 4 & $3,63 \%$ & 28 & $25,45 \%$ & 110 & $100,00 \%$ \\
\hline Sucesso & 10 & $9,09 \%$ & 6 & $5,45 \%$ & 8 & $7,27 \%$ & 0 & $0,00 \%$ & 2 & $1,81 \%$ & 26 & $23,63 \%$ \\
\hline Insucesso & 29 & $26,63 \%$ & 12 & $10,90 \%$ & 13 & $11,81 \%$ & 4 & $3,63 \%$ & 26 & $23,63 \%$ & 84 & $76,37 \%$ \\
\hline Total & 39 & $37,72 \%$ & 18 & $16,35 \%$ & 21 & $19,08 \%$ & 4 & $3,36 \%$ & 28 & $25,45 \%$ & 110 & $100,00 \%$ \\
\hline
\end{tabular}

Fonte: Elaboração própria com dados das Agendas Legislativas da Indústria do Paraná. 
$23,63 \%$. Isto nos leva a refletir a respeito dos objetivos sobre os quais a Agenda Legislativa da Indústria do Paraná é desenvolvida, ou seja, não apenas como documento para apresentar o posicionamento do setor diante de projetos que o impactam diretamente, mas também como apoiar as causas que trazem melhoras significativas para a sociedade como um todo. Os projetos da agenda referentes à política social e à responsabilidade social, muitas vezes, não têm um impacto direto na indústria, de forma que os industriais não demonstram nenhuma mobilização para tais medidas além do mero posicionamento favorável. Dessa forma, quando tratamos da questão do sucesso dos industriais na ação política, os projetos desses dois temas acabam alterando os índices de sucesso sem representar necessariamente uma ação política empresarial. Com este viés social, a ALIPR acaba por apresentar convergência com diversos projetos de lei que não representam impacto direto no setor, com grande chance de serem rejeitados, fazendo com que o índice de sucesso real seja alterado. Essa pode ser uma explicação plausível para as diferenças de índice de sucesso observadas nas proposições em função das áreas temáticas dos projetos de lei.

TABELA 7

SUCESSOS E INSUCESSOS $\times$ STATUS QUO

\begin{tabular}{|l|r|r|r|r|r|r|}
\cline { 2 - 7 } \multicolumn{1}{c|}{} & \multicolumn{2}{c|}{$\begin{array}{c}\text { Muda o } \\
\text { status quo }\end{array}$} & \multicolumn{2}{c|}{$\begin{array}{c}\text { Mantém o } \\
\text { status quo }\end{array}$} & \multicolumn{2}{c|}{ Total } \\
\hline Sucesso & 11 & $10,00 \%$ & 15 & $13,63 \%$ & 26 & $23,63 \%$ \\
\hline Insucesso & 0 & $0,00 \%$ & 84 & $76,37 \%$ & 84 & $76,37 \%$ \\
\hline Total & 11 & $10,00 \%$ & 99 & $90,00 \%$ & 110 & $100,00 \%$ \\
\hline Fonte: Elaboração própria com dados das Agendas Legislativas da Indústria do Paraná.
\end{tabular}

A análise dos resultados dos projetos que podem interferir no status quo permite-nos uma visão mais precisa dos tipos de sucessos e insucessos da indústria. Tais resultados são apresentados na Tabela 7.

Esta tabela nos ilustra que, o que pode parecer um grande insucesso da indústria no processo decisório do Legislativo, num primeiro exame, reveste outra perspectiva quando examinado do ponto de vista de sua repercussão no status quo empresarial. Embora a taxa de insucessos seja alta, nenhum dos insucessos representa uma perda para a indústria, ou seja, projetos aprovados que apresentavam posicionamento divergente, tendo 84 (76,37\%) projetos representados, o que seria uma frustração para o setor, correspondendo a projetos que possuíam posicionamento convergente e foram arquivados. Com relação aos sucessos, 11 proposições sobre as quais o setor havia se posicionado de forma convergente foram sancionadas, o que representaria um ganho real para o setor, enquanto 15 projetos em que o setor apresentou um posicionamento contrário foram arquivados, impedindo assim uma piora na situação do empresariado industrial. É possível, portanto, concluir que a indústria apresenta um alto grau de sucesso em barrar projetos que vão contra seus interesses. Entretanto, para poder confirmar tal suposição seria necessário um estudo qualitativo para avaliar como a indústria agiu ou deixou de agir na tramitação de tais proposições, o que foge ao escopo deste estudo. Pelos dados apresentados fica clara a situação favorável para a indústria com relação ao trâmite dos projetos de seu interesse na As- 
sembleia Legislativa. A literatura menciona que o empresariado apresenta uma ação política em regra reativa. Sua principal forma de atuação na arena legislativa seria o de impedir a aprovação de projetos que vão contra os seus interesses (Diniz, Boschi \& Santos, 2000). Caso apresentasse uma ação propositiva, a tendência seria encontrarmos um sucesso mais elevado na convergência com projetos sancionados.

Estes resultados não correspondem às expectativas dos autores das teses sobre o domínio do empresariado no processo decisório (Offe, 1984), configurando um padrão de comportamento político mais complexo e errático do que o predomínio regular da categoria sobre temas que fazem parte da agenda pública na esfera do Legislativo estadual. Assim, a análise mostrou-nos que, no caso da maioria projetos que a indústria posicionou-se como convergente, estes foram arquivados. Entretanto, praticamente todos os projetos sobre os quais a indústria posicionou-se como divergente, foram rejeitados, tendo sido apenas um aprovado. Isto leva-nos à reflexão desenvolvida anteriormente, de que um projeto pelo qual a indústria se posiciona convergente, quando rejeitado, não significa uma perda da indústria, mas sim o impedimento de ganhar um benefício. Entretanto, quando a indústria adota um posicionamento divergente, isto significa que o projeto em questão pode representar riscos para o setor, como, por exemplo, aumento de custos para a indústria, seja por leis referentes a direito do consumidor, a aumento de impostos ou novas leis de proteção ambiental, por exemplo. Por isso, a aprovação de um projeto pelo qual a indústria posicionava-se divergente é uma derrota "maior" do que o insucesso diante de um projeto sobre o qual o posicionamento da indústria era convergente.

Apesar de, aparentemente, num primeiro momento, haver um grande insucesso da indústria no Legislativo, o fato de os projetos pelos quais ela se posiciona como divergente serem arquivados representa uma vitória política, na maioria dos casos mais relevante, do ponto de vista dos interesses afetados, do que a aprovação de projetos com os quais ela se posiciona de forma convergente.

Procuramos fazer também uma análise da autoria dos projetos, para verificar o posicionamento da indústria quando comparado com os projetos de autoria do Legislativo e do Executivo. Os dados obtidos encontram-se na Tabela 8.

TABELA 8

POSICIONAMENTO DA INDÚSTRIA POR AUTORIA

\begin{tabular}{|l|r|r|r|r|r|r|r|r|r|r|r|r|}
\hline \multicolumn{2}{|c|}{ Convergente } & \multicolumn{2}{c|}{ Divergente } & \multicolumn{2}{c|}{ Total } & \multicolumn{2}{c|}{ Sucesso } & \multicolumn{2}{|c|}{ Insucesso } & \multicolumn{2}{c|}{ Total } \\
\hline Legislativo & 140 & $90,32 \%$ & 15 & $9,68 \%$ & 155 & $100,00 \%$ & 28 & $18,07 \%$ & 127 & $81,93 \%$ & 155 & $100,00 \%$ \\
\hline Executivo & 5 & $71,43 \%$ & 2 & $28,57 \%$ & 7 & $100,00 \%$ & 5 & $71,43 \%$ & 2 & $28,57 \%$ & 7 & $100,00 \%$ \\
\hline Total & 145 & $89,51 \%$ & 17 & $10,49 \%$ & 162 & $100,00 \%$ & 33 & $20,37 \%$ & 129 & $79,63 \%$ & $162 *$ & $100,00 \%$ \\
\hline
\end{tabular}

* Existe um projeto a menos do total por ser de autoria do Tribunal de Contas.

Fonte: Elaboração própria com dados das Agendas Legislativas da Indústria do Paraná. 
Dos projetos que tiveram sua tramitação concluída 155 (95,68\%) são de autoria do Legislativo, enquanto 7 (4,32\%) são de autoria do Executivo. A indústria posicionou -se convergente em relação a $140(86,42 \%)$ projetos de origem legislativa, e divergente em referência a 15 (9,26\%), enquanto com relação aos projetos do Executivo obteve parecer convergente com 5 (3,09\%) projetos e divergente com 2 (1,23\%).

Entretanto, quando se olha os resultados em porcentagem, apesar do pouco número de projetos de autoria do Executivo, existe um sucesso em $71,42 \%$ daqueles de origem do Executivo, e apenas $28,58 \%$ de insucessos, enquanto no caso do Legislativo, existe uma taxa de sucesso de apenas $18,06 \%$, e uma taxa de insucessos de $81,94 \%$. Ou seja, observando a porcentagem de sucessos e insucessos, assim como de convergência e divergência da indústria, encontramos uma taxa de sucesso maior quando o projeto é de autoria do Executivo, o que demonstra que a capacidade de pressão da indústria é maximizada quando ela orienta-se para decisões emanadas do Executivo estadual, ator com maior poder de agenda também nas esferas regionais, como demonstram diversos estudos (Figueirado \& Limongi, 1999; Tomio \& Ricci, 2012). A existência de poucos projetos no Executivo se dá pelo fato de quando este apresenta uma mensagem, ela é prontamente aprovada, muitas vezes em regime de urgência, sendo poucos os casos em que isto não ocorre. Assim, é bastante reduzido o número de projetos de lei que podem constar na Agenda Le-

TABELA 9

POSICIONAMENTO

DA INDÚSTRIA POR PARTIDO

\begin{tabular}{|l|r|r|r|r|r|}
\hline Partido & \multicolumn{1}{|c|}{ Convergente } & \multicolumn{2}{|c|}{ Divergente } & Total \\
\hline DEM & 11 & $100,00 \%$ & 0 & $0,00 \%$ & 11 \\
\hline PDT & 5 & $100,00 \%$ & 0 & $0,00 \%$ & 5 \\
\hline PL & 6 & $85,70 \%$ & 1 & $14,30 \%$ & 7 \\
\hline PMDB & 36 & $85,71 \%$ & 6 & $14,29 \%$ & 42 \\
\hline PMN & 3 & $100,00 \%$ & 0 & $0,00 \%$ & 3 \\
\hline PP & 7 & $87,50 \%$ & 1 & $12,50 \%$ & 8 \\
\hline PPS & 13 & $86,66 \%$ & 2 & $13,33 \%$ & 15 \\
\hline PRB & 1 & $100,00 \%$ & 0 & $0,00 \%$ & 1 \\
\hline PSB & 9 & $100,00 \%$ & 0 & $0,00 \%$ & 9 \\
\hline PSDB & 19 & $100,00 \%$ & 0 & $0,00 \%$ & 19 \\
\hline PSL & 3 & $100,00 \%$ & 0 & $0,00 \%$ & 3 \\
\hline PT & 15 & $83,30 \%$ & 4 & $16,70 \%$ & 19 \\
\hline PTB & 9 & 90,0 & 1 & 10,0 & 10 \\
\hline Total & 137 & 90,13 & 15 & 9,87 & $152 *$ \\
\hline * Dois projetos não entraram na conta por se serem de autoria de mais \\
de um partido. \\
Fonte: Elaboração própria a partir da Agenda Legislativa da Indústria.
\end{tabular}

gislativa. Outro aspecto que corrobora com tal análise, são os projetos por ele vetados. Dos 23 projetos vetados apenas três tiveram sua tramitação concluída, e a favor do veto do Executivo.

Ao cruzar os dados de autoria por partido e sucesso/fracasso dos projetos com o parecer da indústria, podemos também chegar a algumas conclusões que nos fornecem pistas relevantes sobre as características da ação política do empresariado paranaense no período examinado.

Assim, verificamos que indústria se posicionou 100\% convergente em relação aos projetos apresentados por parlamentares do DEM, embora dos 11 projetos apresentados por este partido nenhum deles tenha sido aprovado, o que 
indica portanto uma taxa de $100 \%$ de insucessos ${ }^{9}$. O partido que teve maior presença na agenda legislativa foi também o de maior bancada na Assembleia Legislativa do Estado do Paraná, o PMDB. Dos 42 projetos apresentados por este partido, a indústria se posicionou convergente com 36 projetos e contrária a 6 , resultando num total de 31 insucesso e 11 sucessos. O partido que apresentou uma taxa de sucessos próximo à de insucessos foi o PP, tendo, respectivamente, 4 e 5 sucessos e insucessos. Com relação ao $\mathrm{PT}$, a indústria posicionou-se convergente a 15 projetos e contrária a 4 , obtendo 4 sucessos e 15 insucesso. A indústria posicionou-se convergente em 100\% dos projetos de autoria do PSDB, assim como do PSB e do PDT. Das 19 proposições apresentadas pelo PSDB, apenas uma foi aprovada, resultando em 1 sucesso e 18 insucessos. O PSB apresentou 8 projetos ao total, os quais foram arquivados, resultando em 8 insucessos. Já no tocante ao PDT, dos 5 projetos apresentados, 1 foi aprovado, representando 1 sucesso da indústria e 5 insucessos. O PTB apresentou 10 proposições, das quais a indústria era favorável a 9 e contrária a 1, apresentando 2 sucessos e 8 insucessos.

Em suma, encontramos um posicionamento divergente da indústria predominantemente contra partidos que são da base governista (PMDB, PT), e se enquadram no espectro ideológico centro-esquerda, e um posicionamento $100 \%$ convergente em relação a partidos que são de oposição (PSDB, DEM) e considerados ideologicamente como partidos de centro-direita e, além disso, com vários parlamentares recrutados nas fileiras do próprio empresariado.

\section{Conclusão}

Através de análise da Agenda Legislativa da Indústria do Paraná, pudemos perceber que a grande maioria dos projetos sobre os quais a indústria demonstra interesse, posicionando-se convergente ou divergente, são arquivados, refletindo de certa forma o baixo poder de agendamento dos órgãos legislativos em escala regional. Além disso, observamos que, ao contrário do verificado por outros pesquisadores no Congresso Nacional, existe um alto índice de insucessos do empresariado paranaense no Legislativo, ou seja, a indústria não conseguiu atingir suas demandas em 79,15\% dos projetos de seu interesse que tramitaram na Assembleia Legislativa, tendo sucesso em apenas $20,85 \%$.

Entretanto, quando analisamos se os projetos que foram aprovados ou rejeitados influenciavam de alguma forma o status quo vigente do setor, temos uma nova percepção a respeito dos ganhos e das perdas da indústria no Legislativo. Quando consideramos apenas os projetos que interferem no status quo, todos os que o mudariam para pior (do ponto de vista empresarial) foram arquivados, representando, assim, nenhuma perda para a indústria: 11 dos projetos que mudaram para melhor os status
9. Vale observar que, durante o período em tela, o estado do Paraná foi governado por Roberto Requião, do PMDB, e o DEM esteve na oposição ao governo. 
quo, foram aprovados, o que representa um ganho com índice de $10 \%$ de sucesso em projetos que alteram para melhor a atual situação do empresariado. A grande maioria dos projetos representa uma frustração para a indústria, porque impediu que o status quo melhorasse a seu favor, entretanto não representam perdas diretas para ela. Em nenhum momento o status quo piorou para a indústria, tendo esta resultados positivos ou, na grande maioria dos casos, conseguindo que a situação se mantivesse inalterada.

Outros dois pontos interessantes que devemos destacar é que, apesar do baixo universo de projetos de autoria do Executivo e até mesmo de certos deputados, podemos observar um afinidade entre a indústria e as propostas de autoria governamental, assim como uma afinidade entre a indústria e os partidos do campo político de centro-direita (PSDB e DEM).

Estes resultados permitem-nos concluir que as arenas legislativas estaduais não são um espaço de organização empresarial da mesma importância que o parlamento nacional, refletindo em parte o baixo poder de agenda e baixa capacidade propositiva destes órgãos (Tomio \& Ricci, 2012). Entretanto, isso não equivale a afirmar que a ação legislativa do empresariado nos parlamentos estaduais seja destituída de importância pois, além de dar mais visibilidade a seus pontos de vista, esta ação contribui indiretamente para legitimar o Legislativo estadual como arena relevante de debate e elaboração de políticas governamentais, contribuindo para a progressiva institucionalização do órgão assim como ocorre em outros legislativos estaduais. Além disso, o empresariado obteve algumas vitórias políticas importantes ao evitar que proposições que alteravam o status quo desfavoravelmente a seus interesses fossem aprovadas. Reitere-se, no entanto, que, para afirmar taxativamente que os resultados favoráveis à indústria da tramitação destas proposições legislativas foram provocados por pressão da indústria, seria necessário empreender um estudo mais detalhado de sua atuação como grupo de pressão ao longo da tramitação dos projetos. Entretanto, independente do motivo pelo qual seu deu tal resultado, é possível afirmar que representou um ganho ou uma perda para a indústria na medida em que estes segmentos sociais se posicionaram explicitamente em relação à proposição debatida.

A análise da Agenda Legislativa da Indústria embora, evidentemente, não esgote todas as dimensões do estudo da ação política da Fiep, é de extrema importância para compreender como se desenvolve o processo de influência de tais associações no poder Legislativo pela entidade representativa do empresariado industrial paranaense, bem como para entender melhor a agenda de políticas públicas propostas pela associação. O fato de a federação ter um departamento que cuida da elaboração deste documento, apresentá-lo aos deputados e à opinião pública, e buscar influenciar a elaboração de proposições legislativas mostra que empresariado industrial estadual procura articular-se de forma razoavelmente unitária e coordenada 
para defender os seus interesses, apesar dos conflitos presentes dentro do próprio grupo, tal como evidenciado pelo embate de chapas concorrentes na disputa pela diretoria da federação. Mostra também que, apesar o predomínio do executivo no processo de elaboração de políticas públicas no Brasil, os órgãos legislativos, também em escala regional, vem se constituindo numa importante arena de debates de políticas públicas, provocando a ação organizada de grupos de interesse, o que por fim contribui para o progressivo aumento da qualidade do debate público e dos processos de representação e institucionalização política que ocorrem dentro destes órgãos.

Abstract: The purpose of this paper is to study the degree of success and failure of Federation of Parana State Industry (Fiep) on the proposals submitted at the 16th Legislature (2007-2011) of the Legislative Assembly of Parana. To materialize this purpose, we analyze the convergence rate between the suggestions of Industry Federation of Paraná and the propositions that were processed during the legislature, drawing on the methodology developed by Mancuso (2007) for the analysis of parliamentary action of entrepreneurs. We seek to demonstrate two basis hypothesis: (i) the degree of success of the entrepreneurs of Parana State is smaller than that observed by other authors in Federal Legislature, (ii) the businessmen of Parana State are characterized as a political actor with a low degree of purposeful but with high power veto over the propositions that contradict their interests. Thus, we seek to enter into the debate about the political entrepreneurial action in the post-1988 brazilian political system, highlighting some of its uniqueness and innovative ways of collective action at regional scale.

Keywords: legislative agenda of industry; entrepreneur political action on regional scale; lobbyists on regional scale.

\section{Referências}

ARAGÃO, Murillo de. Grupos de pressão no Congresso Nacional: como a sociedade pode defender licitamente seus direitos no Poder Legislativo. São Paulo: Maltese, 1994.

BARBOSA, Agnaldo de Sousa. Interpretações sobre a burguesia industrial brasileira: um breve balanço. Estudos de Sociologia, n. 15, Araraquara, 2003, p. 31-44.

BOSCHI, Renato Raúl. Elites industriais e democracia: hegemonia burguesa e mudança política no Brasil. Rio de Janeiro: Graal, 1979.

BRAGA, Sérgio; NICOLÁS, Maria Alejandra. Os empresários, a política e a web: mapeando as atividades políticas nos portais das federações de indústrias brasileiras. Sociedade e Estado, v. 24, Universidade de Brasília, 2009, p. 439-490.

COSTA, Paulo Roberto Neves. Democracia nos anos 50: burguesia comercial, corporativismo e parlamento. São Paulo: Hucitec, 1998. 
COSTA, Paulo Roberto; ENGLER, Ícaro. Elite empresarial: recrutamento e valores políticos (Paraná, 1995-2005). Opinião Pública, v. 14, n. 2, Campinas, Nov. 2008.

COSTA, Paulo Roberto Neves; FRANÇA, Andressa. Da responsabilidade social à responsabilidade política: a rede de participação política. In: DALLA COSTA, Armando; MINELLA, Ary; GROS, Denise; MICK, Jacques; ETCHEVERRY, Maria Soledad; IGLECIAS, Wagner. (Orgs.). Desenvolvimento e crise na América Latina: Estado, empresas e sociedade. v. 1. Curitiba: CRV, 2012, p. 179-205.

DINIZ, Eli; BOSCHI, Renato; SANTOS, Fabiano. Elites políticas e econômicas no Brasil Contemporâneo. São Paulo: Fundação Konrad Adenuer, 2000

DINIZ, Eli; BOSCHI, Renato. Empresários, interesses e mercado. Belo Horizonte: UFMG, 2004.

FEDERAÇÃO DAS INDÚSTRIAS DO ESTADO DO PARANÁ. Agendas Legislativas da Indústria, 2005-2011.

FIGUEIREDO, Argelina; LIMONGI, Fernando. Executivo e Legislativo na nova ordem constitucional. Rio de Janeiro: Fundação Getúlio Vargas, 1999.

LEOPOLDI, Maria Antonieta. Política e interesses: as associações industriais, a política econômica e o Estado na industrialização brasileira. São Paulo: Paz e Terra, 2000.

MANCUSO, Wagner Pralon. O lobby da indústria no Congresso Nacional: empresariado e política no Brasil contemporâneo. Dados - Revista de Ciências Sociais, v. 47, n. 3. Rio de Janeiro, 2004, p. 505-547.

- O lobby da indústria no Congresso Nacional: empresariado e política no Brasil contemporâneo. v. 1. São Paulo: Edusp; Humanitas; Fapesp, 2007a.

- O empresariado como ator político no Brasil: balanço da literatura e agenda de pesquisa. Revista de Sociologia e Política, n. 28. Curitiba, Jun. 2007b, p. 131-146.

MARTINS, L. Industrialização, burguesia nacional e desenvolvimento. Rio de Janeiro: Saga, 1968.

MILIBAND, Ralph. The State in capitalist society. New York : Basic, 1969.

OFFE, C. (Org.). Problemas estruturais do Estado capitalista. Rio de Janeiro: Tempo Brasileiro, 1984.

SCHNEIDER, Ben. Business politics and the State in twentieth-century Latin America. New York: Cambridge University, 2004. 
TOMIO, Fabricio; RICCI, Paolo. O governo estadual na experiência política brasileira: as performances legislativas das assembleias estaduais. Revista de Sociologia e Política (Online), v. 20, 2012, p. 193-259.

VOGEL, David. Political science and the study of corporate power: a dissent from the new conventional wisdom. British Journal of Political Science, v. 17, n. 4. Oct. 1987, p. 385-408.

WEYLAND, K. The fragmentation of the business in Brazil. In : DURAND, F.; SILVA, E. (eds.). Organized business, economic change, and democracy in Latin America. Miami: North-South Center, 1998. 
